\title{
Toque De Recolher E A Questão Das Restrições A Direitos Fundamentais Em Tempos De Pandemia
}

\author{
Nilzir Soares Vieira Junior * \\ Universidade Federal de Sergipe, Programa de Pós-Graduação em Direito, Aracaju-SE, Brasil. \\ iD https://orcid.org/0ooo-0003-3936-2896 \\ Henrique Ribeiro Cardoso * \\ Universidade Federal de Sergipe, Programa de Pós-Graduação em Direito, Aracaju-SE, Brasil.
}

iD https://orcid.org/0000-0001-8592-7224

Resumo: Diante da pandemia do novo coronavírus, problematiza-se um conjunto de usos e abusos do poder pela administração pública para responder a essa emergência sanitária. Nesse contexto, o presente trabalho busca analisar a juridicidade das intervenções em direitos fundamentais impostas nos toques de recolher instituídos por decretos municipais. Esse exame se baliza no conceito central de Estado Democrático de Direito, sob os enfoques da separação entre os poderes, da repartição constitucional de competências e do postulado da proporcionalidade. Adota-se o método hipotético-dedutivo, mediante revisão da bibliografia especializada e análise de decisões proferidas pelo Supremo Tribunal Federal no decurso da emergência em saúde. Conclui-se que, mesmo com uma leitura deferente das iniciativas dos poderes políticos durante a pandemia, são ilegítimas as intervenções em direitos fundamentais determinadas nos toques de recolher, podendo caracterizar abuso de poder. Também se conclui pela importância do dever de justificar imposto às autoridades públicas, com ênfase no recurso às evidências científicas e nas informações estratégicas em saúde, exigência para o exercício racional do controle dos atos estatais.

Palavras-chave: Estado Democrático de Direito. Restrições a Direitos Fundamentais. Pandemia. Abuso de Poder.

* Mestrando em Direito pela Universidade Federal de Sergipe. Promotor de Justiça do Ministério Público de Sergipe. E-mail: nilzir@yahoo.com.br

** Doutor em Direito, Estado e Cidadania (UGF/Rio), com Pós-doutorado em Democracia e Direitos Humanos (IGC - Universidade de Coimbra) e Pós-doutorado em Direitos Humanos e Desenvolvimento (PPGCJ/UFPB). Professor do Programa de Pós-graduação da Universidade Federal de Sergipe (Mestrado/PRODIR/UFS); Professor de Programa de Pós-graduação da Universidade Tiradentes (Doutorado/Mestrado/PPGD/UNIT). E-mail: henrique@mpse.mp.br

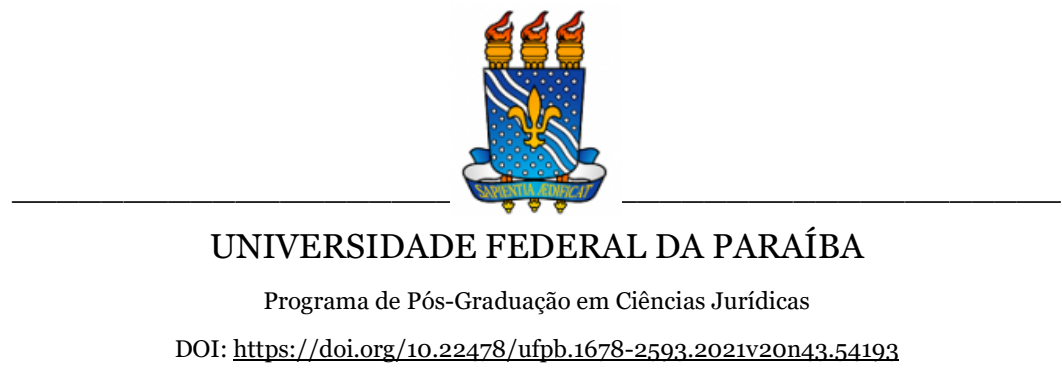




\title{
Toque De Recolher E A Questão Das Restrições A Direitos Fundamentais Em Tempos De Pandemia
}

\author{
Nilzir Soares Vieira Junior
}

Henrique Ribeiro Cardoso

\section{INTRODUÇÃO}

Assiste-se à escalada de um evento global: a pandemia da COVID-19, infecção causada pelo SARS-CoV-2, nova vertente do coronavírus.

Iniciada na província de Hubei, na China, a epidemia rapidamente se alastrou para quase todos os países, produzindo um elevado número de mortes. $\mathrm{Na}$ atualidade, não existe tratamento cientificamente validado para a infecção, de modo que os serviços de saúde geralmente se limitam a tratar os sintomas, para reduzir o desconforto e evitar o agravamento da doença e complicações que levem ao óbito do paciente.

Sobretudo após o reconhecimento da pandemia pela Organização Mundial da Saúde (OMS), em 11/03/2020, os governos nacionais têm adotado uma miríade de providências, visando à contenção do novo vírus e, após iniciada a transmissão comunitária, à diminuição do ritmo de contágio. Logo vieram as quarentenas ao redor do globo, buscando achatar a curva de casos e, com isso, evitar o colapso dos sistemas de saúde e a multiplicação de mortes por desassistência. 
No Brasil, foi aprovada a Lei $\mathrm{n}^{0} 13.979$, de 06/02/2020, que dispõe sobre as medidas para enfrentamento da Emergência em Saúde Pública de Importância Internacional (ESPII), decorrente do coronavírus responsável pelo surto de 2019. Tais medidas visam, em primeiro lugar, impedir ou desacelerar a propagação da enfermidade, entre as quais isolamento e quarentena e, além disso, criar condições materiais para lidar adequadamente com um evento sanitário de tal magnitude, a exemplo da requisição de bens e serviços particulares.

Após a constatação da transnacionalidade da emergência sanitária, e com a crescente atenção da imprensa em torno do tema, divulgando notícias de seus impactos aqui e em outros países, multiplicaram-se, em quantidade e em diversidade, as providências adotadas pela administração pública federal, estadual e municipal, para refrear a disseminação da doença e preservar a capacidade de resposta dos sistemas de saúde.

Trata-se de manifestações do poder estatal que, no intuito de proteger os direitos à vida e à saúde, importam restrições a outros direitos humanos/fundamentais - liberdade (ambulatória), propriedade, trabalho, reunião, bem-estar, entre outros.

Essa "corrida" na tentativa de deter a infecção resultou em medidas que, aparentemente, extrapolam a moldura dada pelo direito vigente, cujo exemplo mais notável são os "toques de recolher" instituídos por meio de decretos municipais ${ }^{1}$.

A esse elenco podem ser agregadas intervenções menos impactantes, mas não menos controversas, como a diminuição da oferta de transporte público urbano, através da diminuição da frota de ônibus circulante ${ }^{2}$; limitação do quantitativo de atendimentos nas

\footnotetext{
1 Em busca realizada no site "Google" com os termos "toque de recolher" e "COVID19 ", foram encontradas diversas notícias acerca da decretação de "toque de recolher" em Campo Grande, Cuiabá e em vários outros municípios brasileiros. Disponível em: www.google.com.br. Acesso em 15.jun.2020.

2 Para ilustrar, o Decreto ${ }^{\circ}$ 6101, de 23/03/2020, do Município de Aracaju, no $\S 10^{\circ}$, de seu art. $5^{\circ}$, previu a redução da frota circulante das empresas de transporte coletivo, em $30 \%$ fora dos horários de pico, em dias úteis; e em $50 \%$ aos sábados, domingos e feriados.
} 
agências bancárias, com agendamento remoto3; e a interdição de praças, calçadões e outros espaços comunitários utilizados para atividades físicas e práticas esportiva. 4

Nesse cenário de contingência, em que as instituições são postas à prova, importa identificar, na ordem constitucional vigente, a moldura normativa à qual devem se ajustar as restrições a direitos fundamentais que, no complexo enfrentamento de uma pandemia, hão de ser legitimamente promovidas para a salvaguarda da vida e da saúde.

A partir desse delineamento, será perquirida a juridicidade das intervenções impostas nos toques de recolher e sua legitimidade no Estado Democrático de Direito, sob os enfoques da separação entre os poderes, da repartição de competências na federação brasileira e do postulado da proporcionalidade.

O estudo das restrições a direitos fundamentais terá como referencial teórico as lições de Robert Alexy e Humberto Ávila. Sem desconhecer a proeminência da "Teoria dos Direitos Fundamentais", de Alexy e sua forte influência na produção científica e na jurisprudência nacionais, este artigo, além de também buscar apoio na “Teoria dos Princípios”, de Ávila, adotará a nomenclatura proposta pelo autor brasileiro, enfocando, entre as espécies normativas, os postulados, normas metódicas que estruturam racionalmente a aplicação dos princípios e regras. Entre essas metanormas se insere a proporcionalidade.

Assume-se a hipótese de que, sem embargo da maior deferência a ser dada às ações estatais de combate à emergência em saúde, no exame de sua juridicidade, as intervenções autorizadas nos decretos de toque de recolher ultrapassam os lindes normativos reconhecidos nessa quadra de excepcionalidade, podendo configurar abuso de poder.

3 Consultar, nesse ponto, o $\S 7^{\circ}$, do art. $2^{o}$, do Decreto ${ }^{\circ} 40.567$, de 25/03/2020, do Estado de Sergipe.

4 Vejam-se os Decretos $n^{\circ}$ s $6.101\left(\S 8^{\circ}\right.$, do art. $\left.5^{\circ}\right)$ e $6.111 / 2020\left(\S 6^{\circ}\right.$, do art. $\left.5^{\circ}\right)$, do Município de Aracaju. 
O trabalho se desenvolverá através do método hipotéticodedutivo, mediante a revisão da bibliografia especializada e pesquisa documental, com foco nas decisões do Supremo Tribunal Federal sobre questões relativas à ESPII, até 31/05/2020, marco estabelecido em consideração às contínuas mudanças de cenário, resultantes da elevada litigância gerada pelo evento em análise.

\section{MARCOS NORMATIVOS PARA O ENFRENTAMENTO DAS EMERGÊNCIAS EM SAÚDE: O CASO DA PANDEMIA DA COVID-19}

Inegável o avanço civilizatório indiciado pelo processo de positivação dos direitos humanos que, ao serem incorporados aos textos constitucionais, assumem o status de direitos fundamentais, passando a ser oponíveis às maiorias democráticas5. Tal blindagem conferida às posições jusfundamentais decorre da supremacia da Constituição no sistema jurídico e das consequentes limitações impostas ao legislador infraconstitucional.

Concebidos para conter a potestade estatal, ainda que consentânea com as transitórias maiorias, os direitos fundamentais, paradoxalmente, passaram a depender cada vez mais do próprio Estado para sua concretização, particularmente os direitos sociais, que demandam prestações positivas, a cargo poder público.

No Brasil, a Constituição de 1988, marco jurídico da superação de um regime político autoritário, que perdurou nas duas décadas anteriores, alinhou, entre seus fundamentos, a cidadania e a dignidade da pessoa humana, conformando o Estado Democrático de Direito 
então inaugurado.

Seguindo esse horizonte axiológico, o Constituinte considerou a saúde direito fundamental, com múltiplas dimensões (social, individual, coletiva e de participação) (SILVA; PESSOA, 2017), impondo ao Estado sua efetivação, mediante políticas sociais e econômicas que visem à redução do risco de doença e de outros agravos e ao acesso universal e igualitário às ações e serviços para sua promoção, proteção e recuperação (CF/1988, art. 196).

Entre as funções do Sistema Único de Saúde (SUS), garantia institucional do direito abordado, está a de executar as ações de vigilância sanitária e epidemiológica (art. 200, II). O $\S 2^{\circ}$, do art. $6^{\circ}$, da Lei $n^{0}$ 8.080/1990, define a "vigilância epidemiológica" como conjunto de ações voltadas para “[...] o conhecimento, a detecção ou prevenção de qualquer mudança nos fatores determinantes e condicionantes de saúde individual ou coletiva, com a finalidade de recomendar e adotar as medidas de prevenção e controle das doenças ou agravos”. O exercício dessa função estratégica se estrutura no "Sistema Nacional de Vigilância Epidemiológica", no qual União, estados, e municípios exercem atribuições comuns e outras específicas, de acordo com os arts. 15 a 19-U, da Lei Orgânica do SUS e a Lei $n^{0} 6.259 / 1975$.

A vigilância em saúde encontra suas raízes em um plexo normativo gradualmente construído no âmbito internacional. A própria natureza dos bens e interesses tutelados pelo direito humano à saúde já intui a transnacionalidade de várias de suas manifestações, de que o monitoramento/resposta às epidemias/pandemias se torna o exemplo mais emblemático.

A história da humanidade há muito conhece medidas destinadas a evitar a proliferação de enfermidades ao redor do mundo. A globalização, que diminuiu as distâncias e tornou mais tênues as fronteiras, favorecendo a circulação de pessoas e bens, também concorreu para a disseminação internacional de doenças.

Para confrontar esse cenário desafiador, a Organização 
Mundial da Saúde (OMS) aprovou, em 2005, o Regulamento Sanitário Internacional (RSI), instrumento normativo que estabelece procedimentos para a proteção à saúde contra a propagação internacional de doenças. O RSI, que entrou em vigor em 2007, vincula todos os Estados-Membros da OMS, salvo a hipótese de recusa ou reserva explícitas, na forma do art. 22, da Constituição da OMS.

Deixando de focalizar doenças específicas, o novo RSI se estrutura a partir da definição de "Emergência de Saúde Pública de Importância Internacional" (ESPII ou PHEIC), assim entendido o evento extraordinário que constitui risco de saúde pública para outro Estado, através da disseminação internacional de doenças, ou que possa exigir uma resposta internacional coordenada.

Conquanto surgida no ano passado, na China, a COVID-19 foi formalmente declarada ESPII apenas em 30/01/2020. Após haver se disseminado por todos os continentes, a infecção pelo SARS-CoV-2 foi caracterizada como pandemia, em 11/03/2020. Desde então, sob o influxo de recomendações da OMS, os governos nacionais vêm adotando diversas medidas de prevenção e de contenção do novo coronavírus.

Após reconhecimento formal da ESPII pela OMS, o Ministério da Saúde editou a Portaria $\mathrm{n}^{0}$ 188/GM/MS, de 04/02/2020, declarando "Emergência em Saúde Pública de Importância Nacional" (ESPIN). No mesmo dia, o Presidente da República encaminhou ao Congresso, em regime de urgência, o Projeto de Lei $n^{0}$ 23/2020, que resultou na Lei ${ }^{0}$ 13.979, de 06/02/2020.

A Lei ${ }^{0} 13.979 / 2020$ elenca, em seu art. $3^{\circ}$, as medidas que as autoridades podem adotar, no âmbito de suas competências, entre as quais: isolamento; quarentena; determinação de realização compulsória de exames, procedimentos e tratamentos de saúde; exumação, necropsia, cremação e manejo de cadáver; requisição de bens e serviços, mediante pagamento posterior de indenização justa; e autorização excepcional e temporária para a importação de produtos sem registro na Agência Nacional de Vigilância Sanitária (ANVISA). Vale anotar que o novo diploma legal traz conceitos claramente 
inspirados no art. $1^{\circ}$, do RSI 2005.

De qualquer modo, todas essas medidas restritivas somente podem ser impostas com base em evidências científicas e em análises sobre as informações estratégicas em saúde e devem ser limitadas no tempo e no espaço ao mínimo necessário $\left(\S^{\circ}\right)$, reconhecendo-se às pessoas atingidas os direitos de informação, de tratamento gratuito e, ainda, de pleno respeito à sua dignidade e aos seus direitos fundamentais $\left(\S 2^{\circ}\right)$.

Por força dos $\S \S 8^{\circ}$ e $9^{\circ}$, do multicitado art. $3^{\circ}$, erigiu-se a necessidade de preservação das atividades e serviços essenciais, assim definidos em decreto do Presidente da República. Com amparo nessa previsão legal, foi editado o Decreto $\mathrm{n}^{0}$ 10.282, de 20/03/2020, elencando os serviços públicos e atividades essenciais, indispensáveis ao atendimento das necessidades inadiáveis da comunidade, assim considerados aqueles que, em sua falta, colocam em perigo a sobrevivência, a saúde ou a segurança da população.

Ainda no plano infralegal, o Ministério da Saúde emitiu a Portaria MS no 356 , de 11/03/2020, com os declarados propósitos de regulamentar e operacionalizar os dispositivos da Lei $n^{0} 13.979 / 2020$, a exemplo dos prazos, condições e procedimentos para o isolamento e a quarentena; procedimento para responsabilização pessoal em caso de descumprimento das medidas; e delimitação das atribuições para o seu acompanhamento.

\section{TOQUES DE RECOLHER, SEPARAÇÃO DE PODERES E ESTADO DE EXCEÇÃO, NO CENÁRIO DA COVID-19}

Desde que a pandemia da COVID-19 se tornou pauta quase exclusiva da imprensa e o assunto onipresente nas redes sociais, 
alcançaram destaque notícias da decretação de toque de recolher em alguns municípios brasileiros.

O termo "toque de recolher" se aplica à proibição, imposta por uma autoridade pública, de que pessoas permaneçam fora de suas residências após determinado horário. Apesar de sua origem nos períodos de guerra, quando soavam sirenes para que a população saísse das ruas, a expressão vem sendo utilizada genericamente para designar impedimentos à circulação em horários específicos. No Brasil, a intervenção vem sendo comumente adotada pelos Juízos da Infância e da Juventude, para vedar a permanência de crianças e adolescentes sozinhos nas ruas à noite, após certo horário, visando coibir a criminalidade e a violência juvenil (SALIBA; BREGA FILHO, 2012, p. 2).

Traz-se, como paradigma para análise, o Decreto $\mathrm{n}^{0}$ 14.216, de 25/03/2020, do Município de Campo Grande, que estabeleceu toque de recolher das $20 \mathrm{~h}$ às $5 \mathrm{~h}$ do dia seguinte, para "confinamento domiciliar obrigatório em todo território".

Para tanto, proibiu-se a circulação de pessoas, exceto quando necessária para acesso aos serviços essenciais ou sua prestação, comprovando-se a necessidade ou urgência (art. $1^{\circ}$ ). Essa restrição à liberdade ambulatória dos cidadãos, no horário de vigência da medida, alcança a circulação em praças públicas municipais, ruas e logradouros, objetivando evitar contatos e aglomerações (art. $3^{\circ}$ ). Para assegurar o cumprimento da regra, facultou-se às autoridades municipais a apreensão de veículos e até condução forçada de pessoas, sem prejuízo da responsabilização pelas infrações administrativas e das comunicações para apuração dos crimes dos arts. 267, 268 e 330, do Código Penal (arts. $2^{\circ}$ e $4^{\circ}$ ).

Divisam-se, nesse ato administrativo normativo, restrições a direitos fundamentais, mormente à liberdade de ir, vir e permanecer sem ser molestado, com o escopo de proteger outros direitos igualmente fundamentais, a vida e a saúde. Sob outra perspectiva, vêse ressurgir a conhecida tensão entre interesses coletivos, ora encabeçados pela segurança sanitária ou pela saúde pública, de um 
lado, e os direitos humanos/fundamentais, do outro.

Partindo da distinção qualitativa entre princípios e regras vista em Dworkin (2002)6 , Alexy (2015, p. 43) depurou-a para estruturar sua "Teoria dos Direitos Fundamentais", a partir da jurisprudência do Tribunal Constitucional Federal da Alemanha (caráter empíricoanalítico), enfocando "a questão acerca da decisão correta e da fundamentação racional no âmbito dos direitos fundamentais" (caráter normativo-analítico).

O mesmo autor conceitua princípios como mandados de otimização, os quais ordenam que algo seja realizado na maior medida possível dentro das possibilidades fáticas e jurídicas. Veiculam, assim, mandamentos prima facie, que comportam satisfação em diferentes graus (ALEXY, 2015, p. 90-106).

A partir da natureza principiológica dos direitos fundamentais, Alexy (2015, p. 276-295) acolhe a teoria externa, que distingue conceitualmente tais direitos das restrições aos bens jurídicos e posições prima facie por estes tutelados. Compreendem-se as restrições como normas sempre compatíveis com a Constituição, diferenciando-se das meras intervenções em direitos fundamentais, que não atendem a essa exigência.

O controle da racionalidade e da juridicidade das restrições a direitos fundamentais perpassa o exame de sua proporcionalidade, que será objeto do último tópico deste ensaio. Por ora, cabe perquirir os contornos das restrições impostas pelo legislador infraconstitucional com a finalidade de proteger a saúde pública, diante da pandemia da COVID-19.

A esse propósito, o art. $2^{\circ}$, da Lei ${ }^{0}{ }^{13} \cdot 979 / 2020$, perfilhando os conceitos do art. $1^{0}$, do RSI 2005, define "isolamento" como a "separação de pessoas doentes ou contaminadas, ou de bagagens,

6 Gomes (2017, p. 2) identifica, no Brasil, uma polarização em Dworkin e Alexy do debate acerca dos princípios, propondo, para o seu enriquecimento, o exame de críticas desenvolvidas por autores alemães sobre "[...] a ponderação alexyana, internamente vinculada à sua compreensão do que sejam princípios jurídicos, direitos fundamentais e o Direito como um todo". 
meios de transporte, mercadorias ou encomendas postais afetadas, de outros, [...]”. Já a "quarentena" constitui a "restrição de atividades ou separação de pessoas suspeitas de contaminação das pessoas que não estejam doentes, ou de bagagens, contêineres, animais, meios de transporte ou mercadorias suspeitos de contaminação, [...]”. Tais medidas objetivam evitar a potencial ou efetiva contaminação ou propagação do vírus.

A Portaria $n^{0}$ 356/2020, do Ministério da Saúde, que regulamenta e operacionaliza os preceitos da Lei $n^{0}$ 13.979/2020, definiu prazos, condições e procedimentos para o isolamento e a quarentena. Em seu art. $5^{\circ}$, prevê que, em caso de descumprimento dessas medidas, caberá ao médico ou ao agente de vigilância epidemiológica informar o fato à autoridade policial e ao Ministério Público, para fins de responsabilização pessoal do infrator.

Como se percebe, as restrições estabelecidas pela Lei $\mathrm{n}^{0}$ 13.979/2020 não afetam a liberdade dos cidadãos com a mesma intensidade das intervenções autorizadas pelos decretos municipais que estabeleceram o toque de recolher. Em vez de regulamentar as disposições da lei de regência, o decreto, ato normativo situado em patamar hierarquicamente inferior, institui diretamente constrangimentos à liberdade dos indivíduos, sem respaldo legal.

Ao editar um ato normativo primário, impondo sujeições aos cidadãos não autorizadas em lei, o Poder Executivo Municipal viola a legalidade, direito fundamental (art. $5^{\circ}$, II, da CF/1988) e princípio da Administração Pública (art. 37), vulnerando, ainda, a separação e a harmonia entre os poderes, princípio fundamental do Estado Democrático de Direito (art. $2^{\circ}$ ).

"Estado de exceção" expressa o modo como o direito reage a situações excepcionais ou, ainda, como se dá a suspensão do próprio direito diante de tais circunstâncias extremas.

Essa noção de estado de exceção como suspensão do direito 
vigente7 foi desenvolvida por Agamben (2003, p. 12) que, ao reconhecer as dificuldades geradas pelas indeterminações - de locus, terminológica e conceitual - do instituto, situa-o em uma "terra de ninguém, entre o direito público e o fato político e entre a ordem jurídica e a vida”.

O filósofo italiano vai além, ao sustentar que o estado de exceção vem se constituindo no paradigma de governo dominante ${ }^{8}$, estruturado sobre a "criação voluntária de um estado de emergência permanente", de que resulta um "patamar de indeterminação entre democracia e absolutismo" (AGAMBEN, 2003, p. 13).

Essa técnica rompe com o equilíbrio entre os poderes políticos, investindo o Poder Executivo de prerrogativas legiferantes, de produzir atos normativos primários dotados de "força de lei", e levando à “erosão” do Parlamento. Tende, aliás, a tornar-se duradoura uma das características essenciais do estado de exceção: a indistinção provisória entre os poderes executivo, legislativo e judiciário. Fica então a democracia presa a um círculo vicioso em que as medidas excepcionais que se justificam para a defesa desse regime acabam conduzindo à sua ruína (AGAMBEN, 2003, p. 19-22).

No Brasil, os regimes que configuram estado de exceção estão disciplinados no texto constitucional, nas disposições que tratam do Estado de Defesa (art. 136, da CF/1988) e do Estado de Sítio (art. 137 a 139).

De acordo com o art. 136, da Carta de 1988, o Presidente da República pode decretar o Estado de Defesa, após ouvir os Conselho da República e de Defesa Nacional, para preservar ou prontamente restabelecer, em locais restritos e determinados, a ordem pública ou a

7 Nas palavras de Agamben (2003, p. 39), “[...] o estado de exceção não é nem exterior nem interior ao ordenamento jurídico, e o problema de sua definição diz respeito a um patamar, ou a uma zona de indiferença, em que dentro e fora não se excluem, mas se indeterminam. A suspensão da norma não significa sua abolição e a zona de anomia por ele instaurada não é (ou, pelo menos, não pretende ser) destituída de relação com a ordem jurídica."

8 Em semelhante direção, Guerra e Guerra Filho (2019, p. 378) vaticinam que o estado de exceção "[...] tende cada vez mais a se apresentar em todo lado, com intensidade variada, como o paradigma de governo dominante na política contemporânea”. 
paz social ameaçadas por grave e iminente instabilidade institucional ou atingidas por calamidades de grandes proporções na natureza. Submeterá, então, no prazo de $24 \mathrm{~h}$, o ato com a respectiva justificação ao Congresso Nacional, que decidirá por maioria absoluta.

Já a decretação do Estado de Sítio, também pelo Presidente da República, mediante prévia autorização do Congresso Nacional, tem lugar nas seguintes hipóteses: a) comoção grave de repercussão nacional ou comprovada ineficácia de medida tomada durante o Estado de Defesa; e b) declaração de guerra ou resposta a agressão armada estrangeira.

A abertura semântica dos termos "ordem pública", "calamidades" e "comoção grave de repercussão nacional" permite que os regimes de exceção disciplinados na Constituição Federal de 1988 alcancem as emergências sanitárias, especialmente as pandemias.

Se a União, detentora da prerrogativa de decretar os estados de defesa e de sítio, não desencadeou o procedimento complexo para o estabelecimento desses regimes excepcionais - envolvendo as cúpulas dos seus Poderes Executivo e Legislativo, decerto não podem os demais entes federativos fazê-lo, mediante a emissão de decretos "com força de lei”, ainda que a pretexto de confrontar a pandemia.

\section{A QUESTÃo FEDERATIVA E A REPARTIÇÃO DE COMPETÊNCIAS NO ENFRENTAMENTO DA COVID-19}

As restrições a direitos fundamentais se originam de normas de competência, que autorizam o Estado a editar normas de conduta aplicáveis coercitivamente aos seus cidadãos.

No estudo dos desenhos institucionais historicamente experimentados para organizar essas competências, tem lugar de destaque a Federação, concebida para compatibilizar, em um equilíbrio dinâmico, as necessidades de uniformidade e de diversidade no exercício do poder político, no território de um Estado. Ínsita à 
ideia de federação é a repartição constitucional de competências entre os entes federados, que estabelecem os fins e os limites do exercício de seus poderes-deveres de editar normas primárias e de produzir atos administrativos e políticas públicas.

A respeito desse arranjo institucional, tem-se o relativo consenso de que o Brasil conta atualmente com um "federalismo cooperativo", marcado pela busca do equilíbrio entre a "homogeneidade", resultado direto do exercício das competências da União e da coordenação de esforços nacionais daí resultantes, de um lado; e a "pluralidade", com a preservação ou reforço da autonomia dos entes parciais, do outro (FISCHER; MACHADO, 2018; KRELL, 2009; BERCOVICI, 2002).

O caráter analítico da atual Constituição e o correspondente detalhamento prescritivo na conformação do federalismo brasileiro deveriam levar, ao menos logicamente, a uma maior segurança na definição das competências constitucionais. Não é isso, porém, o que se nota, por múltiplos fatores, destacando-se: a) ausência de edição das leis complementares de que trata o parágrafo único do art. 23, da CF/1988, para organizar a cooperação interfederativa; e b) ausência de clareza semântica e de uniformidade dos critérios usados pelo Judiciário para definição da competência, quando há divergência a esse respeito entre os entes federados 9 .

Sob outra perspectiva, Fischer e Machado (2018) identificam uma crise do pacto federativo brasileiro, na crescente transferência de atribuições administrativas aos municípios, com a manutenção da hegemonia da União na arrecadação e na repartição das receitas tributárias, em prejuízo da segurança jurídica e das políticas públicas voltadas à efetivação dos direitos sociais.

Esses fatores, incidindo isolada ou cumulativamente, tendem a produzir efeitos disfuncionais no cumprimento das responsabilidades

9 Em estudo comparado com a Suprema Corte norte-americana, Rangel et al (2016) sustentam que o Supremo Tribunal Federal vinha aplicando o critério da "predominância do interesse", para geralmente firmar a competência em favor da União, reforçando a expressiva centralização da República Federativa do Brasil. 
cometidas aos entes políticos, inclusive as relacionadas à proteção e à promoção dos direitos fundamentais e, ainda, na eficácia dos mecanismos democráticos dispostos a manter essa engrenagem em pleno funcionamento.

Em um primeiro plano, retroalimentam os conflitos de competências, quebrando o delicado equilíbrio que se busca alcançar com a forma federativa de estado.

Ainda pior, no entanto, sobretudo no terreno das políticas públicas direcionadas à satisfação dos direitos sociais - a exemplo do direito à saúde -, é o comportamento do ente federativo que, no exercício de suas competências, pauta-se pela inércia, pela indiferença quanto aos objetivos traçados pelo Constituinte, dando ensejo a uma anomalia a que se pode denominar "descentralização por ausência" (BERCOVICI, 2002).

De qualquer modo, na definição de critérios demarcatórios, há de ser respeitada "a especificidade de cada matéria tratada", analisando-se, nos casos concretos, a partir de uma interpretação sistemática do texto constitucional, "se o fortalecimento do poder normativo dos entes políticos inferiores levará também a uma melhoria do bem-estar da população", objetivo maior de um Estado Democrático e Social de Direito (KRELL, 2009, p. 660).

Focalizando essa ordem de ideias na tutela do direito fundamental à saúde, a partir do exame dos arts. 23, II, 24, XII, e 196 a 200, da Constituição de 1988, visualiza-se um modelo organizatório, ainda em construção, revelador de um "federalismo cooperativo sanitário" (RAMOS; MIRANDA NETTO, 2017; DOURADO; DALLARI; ELIAS, 2012). Além das diretrizes constitucionais da descentralização do sistema de saúde e da regionalização da rede de assistência, a definição das competências sanitárias deve nortear-se pelas disposições da Lei $\mathrm{n}^{0}$ 8.080/1990, que parametrizam uma "repartição infraconstitucional de competências" (DOURADO; DALLARI; ELIAS, 2012, p. 22).

Não se pode, contudo, perder de vista a ratio ou o fim último do estabelecimento de tais competências: o de tornar efetivo o direito 
à saúde, em suas múltiplas dimensões. Assim, na interpretação das normas que delimitam os encargos em saúde de cada unidade política, há de se perseguir a máxima efetividade desse direito social.

Postas essas premissas, após a declaração formal da ESPII decorrente da COVID-19, União, estados, DF e municípios, adotaram inúmeras medidas preordenadas à contenção do contágio ou, ao menos, à sua desaceleração. Algumas dessas providências parecem extrapolar do quadro federativo esboçado na Lei Maior, produzindo, assim, conflitos de competência, que também podem vulnerar direitos fundamentais dos cidadãos.

Não se deve olvidar, contudo, que as perplexidades geradas pelos traços de ineditismo da pandemia causada pelo SARS-CoV-2, abordadas ao longo deste trabalho, podem demandar uma modulação do modelo federativo que se tinha até então como ideal, fazendo surgir uma variante mais competitiva do federalismo cooperativo pátrio, orientada pela maximização da proteção do direito à saúde. Essa hipótese parece se confirmar diante da análise de decisões do Supremo Tribunal Federal (STF), durante a emergência sanitária ainda em curso.

Na ADPF $n^{\circ}$ 672/DF, ao conceder medida cautelar, o Ministro Alexandre de Morais assegurou o exercício da competência concorrente dos estados e do DF e suplementar dos municípios, no âmbito de seus territórios, quanto às medidas previstas na Lei $\mathrm{n}^{0}$ 13.979/2020. Legitimou-se o exercício de tais competências, independente da superveniência de ato federal em sentido contrário, sem prejuízo da competência da União para estabelecer medidas restritivas em todo o território nacional, caso venha a entender necessário.

A feição competitiva desse arranjo demandado pela emergência pandêmica também pode ser visualizada na apreciação da cautelar da ADI $\mathrm{n}^{0}$ 6.341-DF. Nessa demanda, partido político buscou ver declarada a incompatibilidade parcial, com a Carta Política, da Medida 
Provisória ${ }^{0} 926 / 2020^{10}$, relativamente às alterações promovidas no art. $3^{\circ}$, caput, incisos I, II e VI, e parágrafos $8^{\circ}, 9^{\circ}, 10$ e 11 , da Lei $n^{\circ}$ 13.979/2020, disposições que pretendem conferir certa homogeneidade, segundo diretrizes federais, aos cerceamentos ordenados pelos entes regionais e locais às liberdades de seus cidadãos.

Ao deliberar sobre o pedido de liminar, o plenário do Supremo, por maioria, deferiu parcialmente a cautelar para dar interpretação conforme ao $\S 9^{\circ}$ do art. $3^{\circ}$ da Lei 13.979/2020, explicitando que, preservada a atribuição de cada esfera federativa, o Presidente da República pode dispor, mediante decreto, sobre os serviços públicos e atividades essenciais.

Da leitura do voto condutor do Ministro Edson Fachin, ressai que a emergência em saúde não outorga "discricionariedade sem controle ou sem contrapesos típicos do Estado Democrático de Direito." (BRASIL, 2020f, p. 33). No exercício de suas competências na área da saúde, as autoridades políticas hão de seguir "parâmetros materiais específicos", devendo sempre justificar suas ações, de modo a permitir o controle a ser exercido pelos demais poderes e pela sociedade.

De qualquer forma, considerou-se a omissão como "pior erro", reputando grave que, sob o pálio da competência exclusiva ou privativa, "premiem-se as inações do governo federal, impedindo que Estados e Municípios, no âmbito de suas respectivas competências, implementem as políticas públicas essenciais." (BRASIL, 2020f, p. 38).

Por outro lado, segundo essa posição majoritária, a União pode afastar a competência dos demais entes, sempre que veicular, "de forma nítida", por lei geral ou complementar, norma organizadora da cooperação federativa , exercendo, assim, a presumption against

10 A Medida Provisória $\mathrm{n}^{0}$ 926/2020 foi convertida na Lei $\mathrm{n}^{0} 14.035$, de 11/08/2020. Entre as alterações promovidas em seu texto, destaca-se a permissão a que o órgão estadual de vigilância sanitária emita recomendação técnica destinada à restrição da locomoção intermunicipal (BRASIL, 2020c). 
preemption. Todavia, no silêncio da União, "não se pode tolher o exercício das competências dos demais entes na promoção de direitos fundamentais" (BRASIL, 2020f, p. 35).

O STF afirmou, ainda, ser a legislação "[o] caminho mais seguro para a identificação do fundamento constitucional do exercício da competência dos entes federados" (BRASIL, 2020f, p. 35). Sendo a Lei $\mathrm{n}^{0}$ 13.979/2020 expressão da competência federal de legislar sobre vigilância epidemiológica, a partir da leitura da Lei no 8.080/1990 e de normas internacionais que estatuem parâmetros regionalizados para o atendimento mínimo à capacidade de vigilância e resposta em saúde, definiu-se que o exercício da competência da União para legislar sobre o tema deve resguardar a atuação dos demais entes federativos.

Na ADI $n^{0}$ 6.343-DF, ajuizada por agremiação partidária, foram questionadas disposições da Lei $\mathrm{n}^{0}$ 13.979/2020 relativas ao transporte de passageiros, especificamente quanto à suspensão das competências estaduais para restringir o transporte intermunicipal (art. $3^{\circ}, \mathrm{VI}$, "b") e, ainda, à disciplina dessa medida por ato conjunto dos Ministros de Estado da Saúde, da Justiça e da Infraestrutura $\left(\$ 6^{\circ}\right)$.

Trazida a plenário a decisão que indeferiu a cautelar, em 06/05/2020, o STF decidiu, por maioria, na linha do voto do Ministro Alexandre de Morais, "suspender parcialmente, sem redução de texto, o disposto no art. $3^{\circ}$, VI, b, e $\S \S 6^{\circ}$ e $7^{\circ}$, II" (BRASIL, 2020g, p. 125126), reconhecendo que estados e municípios podem adotar medidas de restrição aos transportes intermunicipal e local, respectivamente, sem a necessidade de autorização da União. Remanesce, porém, intacta a competência do ente central para decretar medidas desse gênero, quando assim exigir o interesse nacional, reafirmando-se, ademais, a necessidade de lastrear essas intervenções em recomendação técnica e fundamentada e de preservar a circulação de produtos e serviços essenciais, definidos em decreto do ente federativo, nos limites de suas competências.

Depreende-se, assim, das decisões proferidas até o presente 
momento pelo STF, a tendência em se resolver os eventuais conflitos entre os entes federados, prestigiando a conduta daquele que exercer suas competências no sentido de proteger o direito à saúde.

De qualquer modo, nem mesmo essa orientação adotada pelo Supremo - de induzir a ação, em detrimento da omissão -, tem o condão de legitimar os toques de recolher adotados por municípios brasileiros, a pretexto de combater a pandemia e de lidar com seus efeitos.

É que, como ressalvado na decisão plenária proferida na ADI $n^{0}$ 6.341-DF, é a legislação o "caminho mais seguro" para a delimitação das competências dos entes federados no contexto da emergência sanitária. Na hipótese em apreço, pretende-se referir à Lei $n^{0}$ 8080/1990 (Lei Orgânica do SUS) e, mais especificamente, à Lei $n^{\circ}$ 13.979/2020.

Ora, nenhuma das medidas restritivas do art. $3^{\circ}$, da Lei $\mathrm{n}^{0}$ 13.979/2020, ostenta o alcance e a gravidade das intervenções contempladas nos toques de recolher, que autorizam a apreensão de veículos e até a condução forçada de pessoas, sem prejuízo da responsabilização pelas infrações administrativas e das comunicações para apuração criminal.

Depara-se com invasão de competências da União, de acordo com os balizamentos da Carta de 1988, da Lei $n^{0} 8.080 / 1990$ e do Regulamento Sanitário Internacional. Nesse eixo de análise, as normas gerais estão insertas na Lei ${ }^{0} 13.979 / 2020$, que, em seu art. $3^{\circ}$, elenca e delineia as medidas de isolamento, quarentena, e outras restritivas das liberdades individuais, que podem ser adotadas pelos entes políticos, no exercício de suas competências. Nenhuma dessas medidas restritivas de direitos - inclusive da liberdade ambulatória dos cidadãos -, previstas na legislação federal de regência, tampouco em sua regulamentação, dada pela Portaria $n^{0}$ 356/2020, do Ministério da Saúde, oferece paralelo conceitual àquelas autorizadas pelos decretos de toque de recolher.

Em tempos de paz, a liberdade de locomoção somente poderia sofrer cerceamento com essa extensão, na eventualidade de decretação 
Toque De Recolher E A Questão Das Restrições A Direitos Fundamentais Em...

dos estados de defesa e de sítio (CF/1988, arts. 136 a 139), estando ambos os regimes jungidos às competências da União. Sob esse prisma, e a partir das premissas teóricas já vistas em Agamben (2003), os toques de recolher instituem um "estado de exceção", consubstanciando inequívoco abuso no exercício do poder estatal, passível de correção judicial.

A ilegitimidade dessas intervenções é de tal monta que, para além da investigação fundada na manifesta inconstitucionalidade formal dos atos normativos que as veiculam, também se revelam materialmente viciadas, a partir de uma análise pautada pelo postulado da proporcionalidade. É o que se verá a seguir.

\section{O POSTULADO DA PROPORCIONALIDADE NO CONTROLE DAS RESTRIÇÕES IMPOSTAS PELA ADMINISTRAÇÃO SANITÁRIA}

O controle da racionalidade e da juridicidade das restrições a direitos fundamentais encontra na proporcionalidade o seu principal vetor. Ao se observar esse postulado, evita-se que as soluções para situações de colisão entre normas-princípios que veiculam tais direitos recaiam em subjetivismo ou se apoiem em fundamentos insondáveis.

Segundo Alexy (2015, p. 588-611), do enquadramento dos direitos fundamentais como normas-princípios se dessume a "máxima da proporcionalidade", com suas máximas parciais, que permitem compreender como se dá a otimização: a) Adequação: critério negativo, que elimina os meios não adequados; b) Necessidade: exige que, entre os meios aproximadamente adequados, seja selecionado aquele que intervenha de forma menos intensa; e c) Proporcionalidade 
em sentido estrito: coincide com a "lei do sopesamento", parâmetro para solucionar, no plano jurídico, colisões entre princípios ${ }^{11}$.

Devem, ainda, nortear os sopesamentos de direitos fundamentais, sobretudo em situações de incerteza, os "princípios formais", entre os quais se destaca o "princípio formal da decisão por parte do legislador democraticamente legitimado", concernente à "competência decisória do legislador"12.

Ávila (2018, p. 164-203) conceitua "postulados" como normas imediatamente metódicas, que estabelecem critérios de interpretação e de aplicação das outras espécies normativas: regras e princípios. Como já antecipado na parte introdutória, é nessa categoria que o autor enquadra a proporcionalidade, de grande serventia na compreensão dos limites da administração sanitária na imposição de restrições a direitos fundamentais, no combate à COVID-19.

A proporcionalidade impõe aos poderes estatais que elejam, para a realização de seus fins (resultados concretos extrajurídicos), meios adequados, necessários e proporcionais. A aplicação da proporcionalidade envolve, assim, uma "relação de causalidade entre meio e fim, de tal sorte que, adotando-se o meio, promove-se o fim" (ÁVILA, 2018, p. 203).

$\mathrm{O}$ exame da adequação deve admitir que legislador e administrador selecionem um meio que promova minimamente o fim. Para os atos normativos, a medida será adequada, se, abstrata e geralmente, servir de instrumento para a promoção do fim; ao passo que, para os atos individuais, se, concreta e individualmente, cumprirem esse desiderato. De qualquer modo, a qualidade da avaliação deve ser aferida no momento da escolha do meio, de acordo com as circunstâncias que lhe sejam contemporâneas e, não, quando

11 "Quanto maior for o grau de não-satisfação ou de afetação de um princípio, tanto maior terá que ser a importância da satisfação do outro" (ALEXY, 2015, p. 593).

12 Esse princípio formal se relaciona intimamente com o reconhecimento ao legislador de "discricionariedade epistêmica (ou cognitiva)", quando se revela incerto ou inseguro aquilo que é obrigatório, proibido ou facultado, por força dos direitos fundamentais, quanto às suas premissas empíricas ou normativas (ALEXY, 2015, p. 295). 
for eventualmente revista por órgão de controle ou pelo Poder Judiciário (ÁVILA, 2018, p. 210-216).

O exame da necessidade, por sua vez, pressupõe meios alternativos àquele escolhido pelo Poder Público, que igualmente promovam o fim, restringindo com menor intensidade os direitos afetados. Envolve duas etapas de investigação: "exame de adequação dos meios", para verificar se os meios alternativos realizam igualmente o fim; e "exame do meio menos restritivo", para avaliar, entre tais meios, qual o que restringe menos os direitos atingidos (ÁVILA, 2018, p. 216-219).

Com essa mesma orientação, o parágrafo único, do art. $3^{\circ}$, da Lei de Introdução às Normas do Direito Brasileiro, exige que a motivação das decisões proferidas nos âmbitos administrativo, controlador e judicial, demonstre a necessidade e a adequação da medida imposta ou da invalidação de ato, em face das alternativas possíveis.

Por fim, o exame da proporcionalidade em sentido estrito, marcadamente subjetivo, opera-se com a "[...] comparação entre a importância de realização do fim e a intensidade da restrição aos direitos fundamentais" (ÁVILA, 2018, p. 219).

Ávila (2018, p. 220-221) propõe, ainda, critérios para modular a intensidade do controle judicial sobre os atos do Legislativo e do Executivo que restringem direitos fundamentais. O âmbito desse controle e a exigência de justificação da restrição a uma posição jusfundamental deverão ser tanto maiores, quanto maior for: (1) a condição para que se construa um juízo seguro sobre a questão tratada; (2) a evidência do equívoco da premissa da restrição ou de sua justificativa; (3) a restrição ao bem constitucionalmente tutelado; e (4) a importância desse bem. Na direção oposta, tanto menores serão o âmbito de controle judicial e a exigência de justificação, quanto mais: “(1) duvidoso for o efeito futuro da lei; (2) difícil e técnico for o juízo exigido para o tratamento da matéria; e (3) aberta for a prerrogativa 
de ponderação atribuída ao Poder Legislativo pela Constituição.” (ÁVILA, 2018, p. 221).

Tais parâmetros podem nortear não somente o controle da compatibilidade das leis com a Constituição, quanto à racionalidade de seus critérios e aos seus limites, mas todo o controle de juridicidade (ou constitucionalidade) dos atos estatais que exteriorizam o exercício do poder, sejam estes administrativos, legislativos ou jurisdicionais. Incidem não apenas sobre o controle exercido pelo Poder Judiciário, a que cabe dar a última palavra, mas às demais instâncias de controle interno e externo (e.g. Ministério Público, Tribunal de Contas, entre outras) dos atos e políticas emanados do Estado.

Diante de uma emergência em saúde de abrangência global como a COVID-19, as autoridades sanitárias caminham em terreno movediço, no domínio dos conhecimentos empíricos e científicos. A convicção em torno da eficácia de uma estratégia para a contenção da pandemia cambia da noite para o dia.

A propósito, o Supremo Tribunal Federal, na ADI no $5592 / \mathrm{DF}$, reconheceu a aplicação, no direito sanitário, dos princípios formais, originários da área ambiental, "da precaução", que orienta a aplicação do direito no sentido de evitar os riscos (abstratos), em situações de incerteza; e "da prevenção", que pretende elidir a provável ocorrência dos danos em si.

De qualquer modo, as autoridades públicas devem atentar para os estudos já produzidos pelas instituições acreditadas no meio científico e, ainda, orientações dos órgãos de referência nacionais e internacionais, quando da edição de medidas predispostas a tutelar a saúde pública e que, ao mesmo tempo, afetem outros direitos de semelhante envergadura. Parece ter sido esse o intento do legislador federal ao ordenar, no $\S^{\circ}$, do art. $3^{\circ}$, da Lei $n^{\circ} 13.979 / 2020$, que as medidas de prevenção e contenção da nova variedade do coronavírus somente poderão ser determinadas com base em evidências científicas e em análises sobre informações estratégicas em saúde.

A essa altura, ganha importância o dever imposto às autoridades públicas de justificar suas escolhas, corolário dos 
princípios da publicidade, da transparência e, ainda, do Estado Democrático de Direito. Viabiliza-se, com sua estrita observância, não somente o exercício racional das competências dos órgãos de controle - jurisdicional, político e administrativo -, mas também o da "liberdade pública", prerrogativa do povo de conhecer as razões e criticar as decisões de seus representantes ${ }^{13}$.

Como já visto ao longo deste artigo, após a declaração da ESPII decorrente da COVID-19, vários municípios brasileiros adotaram toques de recolher, visando à contenção do vírus ou, ao menos, à diminuição do ritmo de contágio da infecção.

De modo geral, as medidas de combate à pandemia, legislativas ou administrativas, têm como ponto de partida o relativo consenso, já acolhido pela OMS e pelo Ministério da Saúde, de que, na falta de um tratamento eficaz, cientificamente avalizado, o distanciamento/ isolamento social constitui a estratégia adequada para retardar a velocidade de propagação da doença. Essa desaceleração pode ser representada pelo achatamento da curva de casos, que passa a ser perseguido para evitar o colapso dos serviços de saúde e mortes por desassistência.

Também prevalente até o momento a orientação de que o distanciamento deve-se dar no plano horizontal, alcançando indistintamente a maioria da população ${ }^{14} \mathrm{e}$, não apenas, no vertical, focando os grupos de risco (pacientes idosos, ou portadores de comorbidades).

Dessa maneira, as medidas examinadas devem eleger como fins (resultados concretos extrajurídicos) a redução do contágio e, de modo mais factível, de sua velocidade, bem como a preservação da capacidade de resposta dos sistemas de saúde às crescentes demandas assistenciais. Em última análise, mira-se a proteção da saúde pública.

13 Sob esse enfoque, no julgamento do pedido cautelar na ADI no 6341/DF, o Ministro Edson Fachin, em seu voto condutor, enalteceu o "dever de justificação" (ou de fundamentação) das restrições impostas no atual estado de emergência sanitária, para preservar as "liberdades individuais" e a "liberdade pública".

14 Acerca do tema, cf. IMPERIAL COLLEGE COVID-19 RESPONSE TEAM (2020). 
Contudo, tomando-se a proporcionalidade como critério para aferição da juridicidade das intervenções em direitos fundamentais, divisa-se que os toques de recolher, adotados já nos primeiros dias da epidemia, constituem medidas ilegítimas, denotando abuso de poder (excesso de poder ou desvio de finalidade). Essa hipótese se sustenta, ainda que não se desvie do norte apontado pelo princípio da deferência, ainda mais firme diante do caráter técnico dos juízos envolvidos e da incerteza nos prognósticos, que têm sido a tônica na vivência da corrente crise sanitária e social.

Não se desconhece a tese segundo a qual o Estado deve tolerar um nível previsível de desgoverno, mesmo de abuso de poder, como subproduto inevitável para se atingirem fins desejáveis, de interesse público, mormente em situações de crise, a exemplo daquela ora vivenciada, dando forma ao denominado "abuso de poder otimizado" (VERMEULE, 2019).

Sem desconsiderar a quase inevitabilidade da ocorrência de excessos na tela caótica que se defronta, em respeito ao Estado Democrático de Direito, há de se apartar as restrições aos direitos fundamentais, justificadas pela ingente necessidade de tutela da vida e da saúde pública, das intervenções desproporcionais, que indiciam abuso de poder.

Adequados são os meios que promovem os fins. Os toques de recolher criam limitações à liberdade de ir e vir dos cidadãos, em certos dias, horários ou locais, sob a cominação de graves consequências jurídicas para sua inobservância, incluindo a condução forçada do infrator e sua responsabilização criminal. Diante dessa configuração, não pairam dúvidas acerca da eficácia dessas intervenções para promover o distanciamento social e, consequentemente, atingir o escopo final de proteger a saúde pública.

A análise seguinte, pautada pelo exame da necessidade, parece conduzir a conclusões bem diferentes. Tal exame é essencialmente comparativo, pressupondo a investigação de alternativas com efetividade igual ou superior à intervenção que lhe serve de parâmetro e que afetem, com menor intensidade, os outros direitos fundamentais 
atingidos - na hipótese, os direitos ao trabalho, ao bem-estar e, sobretudo, à liberdade (ambulatória).

O isolamento, previsto no art. $1^{\circ}$, do RSI 2005, e nos arts. $2^{\circ}, \mathrm{I}$, e $3^{\circ}$, I, da Lei $n^{0} 13.979 / 2020$, aplica-se em situações mais específicas e pontuais, a partir da identificação de pessoas doentes ou bens contaminados. Bem mais abrangente é a quarentena, que, na dicção do art. $2^{\circ}$, I, da mesma lei, constitui restrição de atividades ou separação de pessoas suspeitas de contaminação das pessoas que não estejam enfermas ou de bens nessa condição, de maneira a evitar a possível propagação do coronavírus. A quarentena serve, assim, a afastar ou diminuir riscos potenciais de disseminação da infecção, intentando reduzi-la.

De modo geral, na emergência sanitária em curso, estados e municípios têm publicado decretos que, com base no art. $3^{\circ}$, II, da Lei $\mathrm{n}^{\mathrm{o}}$ 13.979/2020, impedem o exercício de determinadas atividades econômicas (industriais, comerciais, de prestação de serviços, entre outras), preservando-se aquelas tidas como essenciais, nos termos do Decreto $\mathrm{n}^{0} 10.282 / 2020$.

O cerceamento à liberdade de ir e vir dos cidadãos incide de forma indireta: suspensas as atividades empresariais objeto da quarentena, diminui-se a circulação de trabalhadores e consumidores, promovendo-se o desejado distanciamento social, medida não farmacêutica de prevenção e contenção do contágio.

Manejando a escala triádica proposta por Alexy ${ }^{15}$, toma-se como médio o grau da afetação do direito de liberdade resultante da quarentena implementada através da interdição de parte do setor produtivo. No exercício comparativo exigido no exame da necessidade, é inegável que essa restrição afeta a liberdade de ir e vir dos indivíduos em menor grau do que as intervenções autorizadas nos toques de

15 A partir da adoção de um modelo em três níveis, ou triádico, o sopesamento entre a intensidade da intervenção em um princípio, sempre avaliada no caso concreto, de um lado, e a importância da satisfação do princípio colidente, grandeza dimensionada tanto concreta, quanto abstratamente, de outro, torna possível a imposição de "limites à atividade estatal de forma racional" (ALEXY, 2015, p. 599). 
recolher, entre as quais, a condução forçada de eventuais infratores a repartições policiais, para a formalização de procedimento criminal.

Não é tarefa difícil antecipar as situações de constrangimento a que podem ser submetidos os cidadãos que resolvam desatender esses decretos, ainda que justificadamente.

Mesmo que se venha a adotar medidas de coerção mais severas que a limitação das atividades não essenciais, a exemplo da interdição de vias públicas ou a aplicação de multas aos infratores - o que se admite juridicamente viável, desde que haja previsão legal -, ainda assim, tais intervenções seriam menos intensas que as estabelecidas nos toques de recolher.

Como já anotado, deve-se, de regra, deferência à ponderação realizada pelo legislador. A Lei ${ }^{0}{ }^{13.979 / 2020}$ contemplou restrições que pouco se assemelham, em sua conformação, alcance e gravidade, àquelas estatuídas nos decretos de toque de recolher. Portanto, as intervenções em análise não passam pelo teste da proporcionalidade, em seu viés da necessidade, eis que identificados meios igualmente eficazes para proteção da saúde pública e menos danosos aos demais direitos vulnerados.

Em acréscimo, da leitura do Decreto $\mathrm{n}^{0}$ 14.216/2020, do Município de Campo Grande, tomado como paradigma, observa-se a carência de uma fundamentação consistente, à míngua de uma indicação clara das evidências científicas ou das informações estratégicas em saúde em que se baseia. Essa omissão desconsidera o dever de justificar imposto às autoridades públicas pelo $\S 1^{\circ}$, do art. $3^{\circ}$, da Lei $\mathrm{n}^{0}$ 13.979/2020, dificultando o controle desses atos, seja o institucional, com destaque para o judicial, seja aquele exercido pela sociedade, através dos mecanismos de participação dos cidadãos na formação da vontade do Estado.

A busca da solução de um problema conduz, em realidade, a outros problemas. Como adverte Boaventura de Sousa Santos (2020, p. 13), a pandemia "confere à realidade uma liberdade caótica, e qualquer tentativa de a aprisionar analiticamente está condenada ao 
Toque De Recolher E A Questão Das Restrições A Direitos Fundamentais Em...

fracasso, dado que a realidade vai sempre adiante do que pensamos ou sentimos sobre ela”.

\section{CONSIDERAÇÕES FINAIS}

Sem desconsiderar o ambiente de incertezas, característico da sociedade de risco e, em especial, da emergência sanitária que se vivencia, o presente trabalho buscou investigar a juridicidade dos toques de recolher instituídos em decretos municipais, a pretexto de combater a pandemia da COVID-19.

À luz dos princípios do Estado Democrático de Direito e da separação dos poderes, da repartição constitucional de competências e, ainda, do postulado da proporcionalidade - sob o viés da necessidade -, concluiu-se pela ilegitimidade das intervenções autorizadas nos toques de recolher, caracterizando abuso de poder.

Essa asserção se sustenta ainda que o exame empreendido não tenha negligenciado o princípio da deferência às decisões dos poderes políticos, cuja observância ganha ainda maior relevo no momento atual, em que as restrições a posições jusfundamentais tentam se firmar em solo pantanoso, quanto aos seus pressupostos empíricos, técnico-científicos e até jurídicos.

Deixou-se de investigar o problema formulado sob a lente da proporcionalidade stricto sensu, por se antever que a complexidade e a amplitude da tarefa de sopesar os direitos afetados com aqueles tutelados pelas medidas examinadas extrapolam os limites impostos a este ensaio, perpassando os reflexos econômicos e sociais desta crise sanitária.

Em todos os critérios eleitos para balizar o estudo desenvolvido, avulta a importância do dever de justificar imposto às autoridades públicas, com ênfase no recurso às evidências científicas e às informações em saúde, exigência para o exercício racional do controle 
dos atos estatais, seja o institucionalizado, encimado pelo controle judicial, seja aquele vinculado a outros mecanismos democráticos protagonizados pelos cidadãos.

Retomando as lições de Boaventura de Sousa Santos (2020), o futuro pode exigir uma distinção não apenas entre Estado democrático e Estado de exceção, mas entre Estado de exceção democrático e Estado de exceção antidemocrático.

Ainda que se tenha presente a inevitabilidade fática de abusos eventuais no desenhado cenário de emergência, a contenção do arbítrio e a valorização dos direitos fundamentais despontam como missões inafastáveis do Estado Democrático de Direito.

Data de Submissão: 28/07/2020

Data de Aprovação: 01/03/2021

Processo de Avaliação: double blind peer review

Editor Geral: Jailton Macena de Araújo

Editor de Área: Jailton Macena de Araújo

Assistente Editorial: Andréa Neiva Coelho

\section{REFERÊNCIAS}

AGAMBEN, Giorgio. Estado de exceção. Tradução: Iraci D. Poleti. São Paulo: Boitempo Editorial, 2003.

ALEXY, Robert. Teoria dos Direitos Fundamentais. São Paulo: Malheiros, 2015.

ARACAJU. Decreto 6.101 de 23/o3/2020. Disponível em: https://www.legisweb.com.br/legislacao/?id=391544. Acesso em: 30.abr.2020.

ÁVILA, Humberto. Teoria dos Princípios: da definição à aplicação dos princípios jurídicos. 18 ed. São Paulo: Malheiros Editores, 2018. 
Toque De Recolher E A Questão Das Restrições A Direitos Fundamentais Em...

BERCOVICI, Gilberto. A descentralização de políticas sociais e o Federalismo Cooperativo Brasileiro. Revista de Direito Sanitário, São Paulo, v. 3, n. 1, p. 13-28, mar.2002.

BRASIL. Constituição da República Federativa do Brasil de 5/10/1988. Brasília, DF, 5 out. 1988. Disponível em:

http://www.planalto.gov.br/ccivil 03/constituicao/constituicao.htm . Acesso em: 31.mar.2020.

BRASIL. Decreto 10.282 de 20/o3/2020. Brasília, DF, 20 mar. 2020a. Disponível em:

http://www.planalto.gov.br/ccivil_03/_Ato2019-

2022/2020/Decreto/D10282.htm. Acesso em: 31.mar.2020.

BRASIL. Decreto-Lei 4.657, de o4/o9/1942. Brasília, DF, 4 set. 1942. Disponível em:

http://www.planalto.gov.br/ccivil_03/_Ato2019-

2022/2020/Decreto/D10282.htm. Acesso em: 30.abr.2020.

BRASIL. Lei 6.259 de 30/10/1975. Brasília, DF, 30 out. 1975.

Disponível em:

http://www.planalto.gov.br/ccivil_03/leis/L6259.htm. Acesso em: 31.mar.2020.

BRASIL. Lei 8.o8o de 19/o9/1990. Brasília, DF, 19 set. 1990. Disponível em:

http://www.planalto.gov.br/ccivil_o3/leis/18080.htm. Acesso em: 31.mar.2020.

BRASIL. Lei 13.979 de o6/o2/2020. Brasília, DF, 6 fev. $2020 b$. Disponível em: http://www.planalto.gov.br/ccivil_o3/_ato20192022/2020/lei/L13979.htm. Acesso em: 31.mar.2020.

BRASIL. Lei 14.035 de 11/o8/2020. Brasília, DF, 11 ago. $2020 c$. Disponível em: http://www.planalto.gov.br/ccivil_03/_ato20192022/2020/lei/l14035.htm. Acesso em: 12 fev. 2021.

BRASIL. Ministério da Saúde. Portaria no 356 de 11/o3/2020. Brasília, DF, 11 mar. 2020d. Disponível em: http://www.in.gov.br/en/web/dou/-/portaria-n-356-de-11-demarco-de-2020-247538346. Acesso em: 04.jun.2020.

BRASIL. Supremo Tribunal Federal. Arguição de Descumprimento de Preceito Fundamental 672/DF. Brasília, DF, 8 abr. 2020e. Disponível em:

http://portal.stf.jus.br/processos/detalhe.asp?incidente $=5885755$. Acesso em: 30.abr.2020. 
BRASIL. Supremo Tribunal Federal. Ação Direta de

Inconstitucionalidade 5592/DF. Brasília, DF, 4 abr. 2019.

Disponível em:

http://portal.stf.jus.br/processos/detalhe.asp?incidente $=5054307$.

Acesso em: Acesso em: 30.abr.2020.

BRASIL. Supremo Tribunal Federal. Ação Direta de

Inconstitucionalidade 6341/DF. Brasília, DF, 15 abr. 2020 .

Disponível em:

http://portal.stf.jus.br/processos/downloadPeca.asp?id=153449647

20\&ext=.pdf. Acesso em: 21 fev. 2021.

BRASIL. Supremo Tribunal Federal. Ação Direta de

Inconstitucionalidade 6343/DF. Brasília, DF, 6 maio 2020 .

Disponível em:

http://portal.stf.jus.br/processos/downloadPeca.asp?id=1534498491 7\&ext=.pdf. Acesso em: 21 fev. 2021.

CAMPO GRANDE. Decreto 14.216 de 25/o3/2020. Disponível em: http://www.campogrande.ms.gov.br/sesau/downloads/decreton-14-216-de-25-de-marco-de-2020-toque-de-recolher-covid-19campo-grande-ms/. Acesso em: 30.abr.2020.

CARDOSO, Henrique Ribeiro. Proporcionalidade e

Argumentação. A Teoria de Robert Alexy e seus pressupostos filosóficos. Curitiba: Juruá Editora, 2009.

DOURADO, Daniel de Araújo; DALLARI, Sueli Gandolfi; ELIAS, Paulo Eduardo Mangeon. Federalismo Sanitário Brasileiro:

perspectiva da regionalização no sistema único de saúde. Revista de Direito Sanitário, São Paulo, v. 12, n. 3, p. 10-34, nov.2011/fev.2012.

DWORKIN, Ronald. Levando os Direitos a Sério. Tradução de Nelson Boeira. São Paulo: Martins Fontes, 2002.

FISCHER, Octavio Campos; MACHADO, Luciano Marlon Ribas. Pacto Federativo em Crise: Uma Análise na Visão dos Municípios da Segurança Jurídica e da Dignidade Humana. Revista Jurídica, vol. 04, $\mathrm{n}^{\circ}$. 53, Curitiba, 2018. pp. 233-254.

GOMES, Davi F. L. Novas possibilidades para o debate nacional acerca dos princípios: sobre "Crítica da Ponderação: Método Constitucional entre a Dogmática Jurídica e a Teoria Social”. Prim@ Facie, v. 16, n. 33, 2017.

GUERRA, Paola Cantarini; GUERRA FILHO, Willis Santiago. Breve alusão ao atual Estado (Inconstitucional) de Exceção em que estamos vivendo e morrendo. Revista Jurídica, vol. 04, $\mathrm{n}^{\circ}$. 57, Curitiba, 2018. pp. 374-398. 
IMPERIAL COLLEGE COVID-19 RESPONSE TEAM. Report 9: Impact of non - pharmaceutical interventions (NPIs) to reduce COVID - 19 mortality and healthcare demand. 16 March 2020. Disponível em: https://www.imperial.ac.uk/media/imperialcollege/medicine/sph/ide/gida-fellowships/Imperial-CollegeCOVID19-NPI-modelling-16-03-2020.pdf. Acesso em 13 de abril de 2020.

KRELL, Andreas J. A Necessária Mudança de Foco na Implantação do Federalismo Cooperativo no Brasil: da Redefinição das Competências Legislativas para o Desenho de Formas Conjuntas de Execução Administrativa. In: SOUZA NETO, Cláudio Pereira de; SARMENTO, Daniel; BINENBOJM, Gustavo (Coordenadores).

Vinte Anos da Constituição Federal de 1988. Rio de Janeiro: Editora Lúmen Júris, 2009.

RAMOS, Edith Maria Barbosa; MIRANDA NETTO, Edson Barbosa de. $\mathrm{O}$ federalismo e o direito à saúde na Constituição Federal de 1988: Limites e possibilidades ao estabelecimento de um autêntico Federalismo Sanitário Cooperativo no Brasil. Revista Jurídica, vol. 04, $\mathrm{n}^{\circ}$. 49, Curitiba, 2017. pp. 304-330.

RANGEL, Henrique; FADEL, Alexandre Fadel; NERI, Bianca Neri; BOLONHA, Carlos. Judicialização do federalismo e federalismo formal. Revista Direito GV, São Paulo, V. 12, n. 1, p. 217-250, jan./abr.2016.

SALIBA. Maurício Gonçalves; BREGA FILHO, Vladimir. Toque de Recolher: Reflexões acerca de sua utilidade e constitucionalidade. Revista Argumenta - UENP Jacarezinho, $\mathrm{n}^{0}$ 17, p. 303-319, 2012.

SANTOS, Boaventura de Sousa. A cruel pedagogia do vírus. Coimbra: Almedina, 2020.

SERGIPE. Decreto 40.567 de 24/o3/2020. Disponível em: https://www.se.gov.br/uploads/download/midia/12/8e27be55ccfddf d7c243b7d57000211c.pdf. Acesso em: 30.abr.2020.

SILVA, Orlando Sampaio de Almeida Monteiro da; PESSOA, Flávia Moreira Guimarães. A Efetivação Democrática do Direito à Saúde Mediante a Tutela Coletiva e o Incidente de Coletivização de Demandas Individuais. Prim@ Facie, v. 16, n. 32, 2017.

VERMEULE, Adrian. Optimal abuse of power. Administrative Law Review, Rio de Janeiro, v. 278, n. 3, p. 15-43, Sep./Dec. 2019. 
WORLD HEALTH ORGANIZATION (WHO). Constitution Of The World Health Organization. Disponível em:

https://www.who.int/governance/eb/who_constitution_en.pdf. Acesso em 25.mai.2020.

WORLD HEALTH ORGANIZATION (WHO). Dashboard Coranavirus (COVID-19). 11 de maio de 2020. Disponível em: https://who.sprinklr.com/. Acesso em 11.mai.2020.

WORLD HEALTH ORGANIZATION (WHO). International Health Regulations. 2005. Disponível em:

https://apps.who.int/iris/bitstream/handle/10665/246107/9789241 580496-

eng.pdf;jsessionid=4BCo6375BDA45EoEB4848C1AE8A33D85?sequ ence $=1$. Acesso em 30.mar.2020. 


\title{
Curfew And The Question Of Fundamental Rights Restrictions In Pandemic Times
}

\author{
Roberto Leonardo da Silva Ramos
}

\begin{abstract}
Faced with the pandemic of the new coronavirus, a set of uses and abuses of power by the public administration is problematized to respond to this health emergency. In this context, the present study aims to analyze the legality of interventions in fundamental rights imposed on curfews instituted by municipal decrees. This examination is based on the central concept of the Democratic State of Law, under the focus of the separation between powers, the constitutional division of powers and the principle of proportionality. The hypothetical-deductive method is adopted, through a review of the specialized bibliography and analysis of Supreme Federal Court's decisions during the sanitary emergency. It is concluded that, even with a respectful reading of the actions of the political powers during the pandemic, interventions in fundamental rights determined in curfews are illegitimate, which may characterize abuse of power. It is also concluded by the importance of duty to justify of the public authorities, with an emphasis on the use of scientific evidence and strategic health information, a requirement for the rational exercise of control over state acts.
\end{abstract}

Keywords: Democratic State of Law. Fundamental Rights Restrictions. Pandemic. Power abuse. 